\title{
РОЛЬ СТАНДАРТОВ В ОБЕСПЕЧЕНИИ КАЧЕСТВА ЮРИДИЧЕСКИХ УСЛУГ ДЛЯ НАСЕЛЕНИЯ
}

\begin{abstract}
АНнОтАЦИЯ. В статье рассматривается система существующих стандартов качества юридических услуг для населения, выясняется, что единых стандартов качества юридических услуг в современной России не существует, а есть лишь стандартные правила, в недостаточном объеме включенные в массивы нормативного материала, либо корпоративные стандарты, представленные в негосударственном секторе нормотворчества, созданные ассоциациями юристов либо юридическими фирмами. Последними стандартами устанавливаются правила общения с клиентом и условия оказания юридических услуг. Исследуются преимущества и недостатки таких стандартов. Анализируется, каким образом отсутствие единых стандартов качества услуг негативно влияет на правовую жизнь российского общества. Рассматриваются причины правовой малограмотности и низкого уровня правовой культуры значительной доли населения России, неразвитость правового просвещения на уровне государства. Обосновывается целесообразность разработки и утверждения единых стандартов качества юридических услуг. Разработка и внедрение стандартов качества необходимы современному профессиональному сообществу юристов и получателям услуг, поскольку напрямую будут способствовать повышению качества юридической деятельности для населения.

кЛЮЧЕВЫЕ СЛОВА. Юридические услуги; коммерческие юридические услуги для населения; качество юридических услуг; стандарты качества; правовая грамотность населения.

ИНФОРМАЦИЯ О СТАТЬЕ. Дата Поступления 31 июля 2017 г.; дата принятия к печати 11 октября 2017 г.; дата онлайн-размещения 25 октября 2017 г.
\end{abstract}

Yu. O. Baranova Baikal State University, Irkutsk, Russian Federation

\section{ROLE OF STANDARDS IN PROVIDING QUALITY LEGAL SER VICES TO THE PUBLIC}

ABSTRACT. The article examines the existing system of quality legal services to the public. It appears that unitary standards of quality legal services do not exist in modern Russia, there are only standard rules included in insufficient volume in the blocks of normative materials or the corporative standards presented in the nongovernmental rulemaking sector created by the bar associations or law firms. The latest standards establish rules of communication with clients and terms of providing legal services. The article studies advantages and disadvantages of such standards. It analyses the way how the lack of unitary standards in the quality of services adversely affects the legal life of the Russian society. It examines the causes of legal illiteracy and a low level of legal culture of a significant proportion of the Russia's population, the underdevelopment of legal education at the state level. The article substantiates the expediency of developing and approving unitary standards of quality of legal services. Development and implementation of quality standards are necessary for the modern professional community of lawyers and service recipients, since it will directly contribute to improving the quality of legal activities to the public.

KEYWORDS. Legal services; commercial legal services to the public; quality of legal services; quality standards; legal literacy of population.

ARTICLE INFO. Received July 31, 2017; accepted October 11, 2017; available online October 25, 2017.

\section{Baikal Research Journal}


Стандарты качества юридических услуг необходимы для того, чтобы установить официальные критерии, по которым можно определить, оказана услуга клиенту качественно или нет. В первую очередь, разработка стандартов качества юридических услуг должна быть направлена на защиту прав потребителя, так как в большинстве случаев именно потребитель страдает из-за отсутствия четких требований к предоставлению коммерческих юридических услуг. Таким образом, клиент, не знающий, что именно должно входить в состав услуг, может оказаться в неблагоприятной ситуации. Отсутствие знаний о стандартах юридических услуг является причиной завышенных ожиданий от работы юриста, возможности попасть в ситуацию неполного предоставления услуг и, как следствие, разочарования в результатах услуги. На работу юристов отсутствие стандартов качества также может влиять негативно: у юриста нет образца определенных действий, выполнение которых необходимо при работе с клиентом. В результате юрист, честно выполняя свои обязанности, не может быть до конца уверен в том, что предоставленная им услуга объективно является качественной.

O стандартизации юридических услуг написано небольшое количество научных работ. Если же говорить о публикациях с позиций менеджмента услуг, то приходится констатировать лишь отдельные работы [1, с. 134; 2, с. 147].

Все публикации, посвященные теме стандартизации качества юридических услуг, в основном сводятся к ряду основательных трудов Р. Г. Мельниченко [3, с. $26 ; 4$, с. $29 ; 5$, с. 23]. Также можно встретить немногочисленные обращения других ученых к этой теме: А. Н. Чашин [6, с. 18], А. А. Воронова [7, с. 37], В. В. Горовенко [8, с. 236] и др. Специфика данной проблемы в том, что она находится в двух плоскостях: права и экономики.

В России уже довольно долгое время профессионалами обсуждаются предложения о создании и утверждении стандартов качества юридических услуг. Р. Г. Мельниченко, например, говорит о том, что для создания в нашей стране результативной системы оказания юридических услуг за счет государства, в частности, юридической помощи, необходимо создать стандарт качества юридических услуг. Если такой стандарт не будет соблюдаться субъектами оказания услуг, тогда их необходимо лишать возможности предоставлять юридические услуги за счет государства. В настоящее время, создание и введение единых стандартов качества юридических услуг в виде, например, закона, постановления правительства и т.п. в России не происходит [9, с. 241].

Хотя еще в 2011 г. Министерством Юстиции был опубликовал проект Государственной программы Российской Федерации «Юстиция» [6, с. 9]. Данным проектом предусматривалось введение стандартов качества юридических услуг. Но до настоящего времени стандарты даже не разработаны.

Более того, в 1999 г. в России произошла отмена лицензирования юридических услуг. Оказывать такие услуги стало доступно любому, даже малограмотному и судимому человеку. В начале 90 -х гг. предоставлять коммерческие юридические услуги в России могли только лицензированные субъекты. В положении о лицензировании деятельности по оказанию таких услуг указывалось, что услуги могут оказывать физические лица, имеющие стаж работы по юридической специальности не менее трех лет и диплом о высшем юридическом образовании. Но в 1999 г. такое положение было отменено постановлением Правительства РФ от 20.05.1999 г. № 548 «О признании утратившими силу решений Правительства Российской Федерации по вопросам лицензирования отдельных видов деятельности». Отмена лицензирования платных юридических услуг вызвала справедливую критику со стороны мирового сообщества юристов.

\section{Baikal Research Journal}


Таким образом, сегодня в России юридические услуги физическим и юридическим лицам предоставляются двумя категориями субъектов: адвокатами, которые обязаны гарантировать качество своих услуг, но не могут обещать положительный результат, и всеми другими физическими и юридическими лицами, которые вправе обещать положительный результат своей работы, но не гарантируют качества оказанных ими услуг. Для этих двух групп субъектов существует разное государственное регулирование. Чтобы получить статус адвоката, необходимо соответствовать государственным профессиональным требованиям, а именно: иметь высшее юридическое образование, стаж работы по специальности, пройти сложный квалификационный экзамен, не иметь судимости и т.д.

К другим же субъектам, оказывающим коммерческие юридические услуги, никаких требований законодательство не предъявляет. Эти производители услуг не обязаны иметь высшего юридического образования и стажа работы. Вполне достаточно с 18-летнего возраста, сразу после окончания школы, дать объявление в газету об оказании юридических услуг и практиковать право по своему разумению.

Такую ситуацию нельзя считать нормальной, так как нет гарантии, что оказанная юридическая услуга является квалифицированной, то есть в данном случае нарушается один из принципов оказания любой услуги - обеспечение качества.

Заместитель министра юстиции Ю. Любимов по этому поводу справедливо указывает, что без наличия стандартов качества невозможно изменить ситуацию на рынке юридических услуг. В настоящее время существуют отдельные правила для адвокатов и различные стандарты, которые самостоятельно создают для себя юридические фирмы, чтобы конкурировать на рынке, но ответственности за качество предоставляемых услуг нет ни у адвокатов, ни у остальных субъектов. Ю. Любимов предлагает два способа создания стандартов качества: первый разработать для субъектов, не имеющих адвокатского статуса свой обязательный стандарт, второй способ - оставить возможность оказывать юридические услуги только адвокатам [6, с. 12].

Некоторые субъекты рынка юридических услуг высказываются против создания единых стандартов качества, к примеру, адвокатское руководство негативно относится к созданию и введению таких стандартов. По их мнению, главной гарантией качества услуг должен быть статус адвоката, так как его наличие гарантирует соблюдение адвокатом тех норм и правил, которые закреплены в законодательстве, в частности, в Кодексе профессиональной этики. Но есть и слабые стороны такой позиции.

Во-первых, адвокатские стандарты распространяются только на адвокатов, а оказывать юридические услуги в нашей стране вправе и другие субъекты. Следовательно, если отказаться от идеи создания отдельных стандартов для иных субъектов, нужно оставить право оказывать юридические услуги только лицам, имеющих статус адвоката.

Во-вторых, действующие для адвокатов нормы недостаточны, так как, в основном, они направлены на этику взаимоотношений с клиентом, а сам процесс оказания услуги практически не затрагивается. Таким образом, необходимо создание стандартов, устанавливающих конкретные правила, которые обеспечивали бы защиту прав клиентов.

Особо пагубным представляется оказание коммерческих услуг по представительству в судах без опоры на обязательные стандарты. Поскольку нет обязательных стандартов услуг по представительству в судах, их оказание доступно любым производителям. Дело в том, что качество судебного представительства интересов клиента осуществить труднее [5, с. 359]. Юрист должен подготовить исковое заявление, собрать доказательства по делу, если получить их нет возможности,

\section{Baikal Research Journal}

электронный научный журнал Байкальского государственного университета 
то необходимо подготовить ходатайство в суд для истребования доказательств и др. Это сложный комплекс работ, для которого требуется профессионально-корректная деятельность.

Обсуждая данную проблему, А. Н. Чашин считает, что юристы как производители услуг хотели бы взять на себя все необходимые обязательства (перечень обязательных требований, критерии допуска к юридической деятельности и т.п.) и соблюдать установленные стандарты качества услуг, но, к сожалению, такие стандарты отсутствуют [6, с. 29].

Однако стандарты качества юридических услуг имеют ценность не только для производителей, но и для потребителей.

По сути, юрист только помогает защищать права своего клиента. А клиент сам принимает решение, пользоваться ли своими правами и каким образом. Означает ли это, что клиент может не участвовать в процессе, передав все полномочия и выдав юристу доверенность? К сожалению, нет. Без взаимодействия с клиентом юристу невозможно узнать и доказать все обстоятельства дела. Поэтому взаимодействие юриста и клиента - важное условие предоставления услуги. Клиент фактически становится «сопроизводителем» услуги, и от результативности такого «сопроизводства» напрямую зависит уровень качества услуги [10, с. 132].

Обсуждая роль клиента в обеспечении качества юридических услуг, нельзя не отметить проблему асимметрии информации. Клиенту трудно оценить сложность своей правовой проблемы, возможные варианты ее решения, а также профессионализм юриста, и, как следствие, качество юридической услуги. Он даже примерно не может себе представить, какой именно она должна быть, каким критериям соответствовать. И недобросовестные юристы с легкостью могут воспользоваться отсутствием знаний у клиента и его доверием. Бывают случаи, когда после проигрыша дела юрист уклоняется от общения с клиентом, опасаясь неприятного разговора по поводу возвращения гонорара и т.д. Бывает и наоборот, когда клиенты беспокоятся за свою правовую ситуацию, начинают постоянно звонить юристу и такие разговоры могут продолжаться довольно длительное время. Пользы для дела такое общение не несет, клиенту просто нужно «выговориться». Если работник не отвечает на звонки, могут начаться жалобы в разные инстанции по поводу того, что юрист уклоняется от общения с клиентом. Чтобы не возникало таких ситуаций, в стандарте качества оказания услуг должны быть указаны условия общения юриста с клиентом, например, систематичность и методы общения сторон, координация времени общения и т.п. Это, в частности, позволит юристу планировать свое рабочее время, так как в силу своей профессиональной деятельности - из-за командировок, участия в судебных заседаниях, юрист не может постоянно находиться в офисе.

Таким образом, можно утверждать, что в стандартах качества юридических услуг заинтересованы все участники производства и потребления услуг.

Представляется, что стандарты качества юридических услуг могут быть классифицированы следующим образом: а) стандарты международных организаций; б) государственные стандарты; в) стандарты профессиональных сообществ (принятые ассоциациями и другими объединениями юридических организаций); г) стандарты отдельных юридических фирм или организаций, предпринимателей.

Оставляя за рамками международные стандарты, рассмотрим российские нормы, регулирующие качество юридических услуг для населения.

Государственные стандарты содержатся в Федеральном законе «Об адвокатской деятельности и адвокатуре в Российской Федерации» от 31.05.2002 г. № 63ФЗ и в «Кодексе профессиональной этики адвоката» (принят Первым Всероссийским съездом адвокатов 31.01.2003 г.). Однако, эти нормы обязательны только

\section{Baikal Research Journal}

электронный научный журнал Байкальского государственного университета 
для адвокатской деятельности. Права и обязанности адвоката по поводу представительства в судах прописаны в процессуальных кодексах. Также следует отметить Федеральный закон «О бесплатной юридической помощи в Российской Федерации” от 21.11.2011 № 324-ФЗ, который регулирует соответствующий аспект адвокатской деятельности.

Особое внимание следует уделить ст. 25 Федерального Закона «Об адвокатской деятельности и адвокатуре в Российской Федерации», а именно соглашению об оказании правовой помощи, которое отчасти является гарантией качества юридических услуг. Данное соглашение регулирует отношения адвоката и клиента. Это гражданско-правовой договор, который заключается в письменной форме между клиентом и адвокатом для соблюдения интересов обеих сторон.

В Федеральном законе «Об адвокатской деятельности и адвокатуре в Российской Федерации» описаны принципы, на которых строится работа адвоката, его права и обязанности, организация деятельности, его статус, частично содержатся стандарты качества услуг, но они недостаточны, так как в них практически не говорится о самом процессе оказания услуги.

«Кодекс профессиональной этики адвоката» содержит нормативные предписания, устанавливает обязательные правила на основе критериев нравственности и традиций адвокатуры и имеет обязательную силу для адвокатов, а не рекомендательную. В Кодексе содержатся не только правовые, но и нравственные аспекты общения адвоката с клиентом. Следует обратить внимание на требования разумности принятия поручения. Адвокат принимает поручение от клиента даже в случае, когда у него есть сомнения юридического характера.

Кроме государственных стандартов существует и профессиональное регулирование качества юридических услуг. Устав ждать от государства наведения порядка в сфере платной юриспруденции, сообщества юристов, без участия государства, разрабатывают и внедряют свои стандарты качества, публикуют их на своих сайтах в интернете.

Следует отметить удачный опыт принятия профессиональных стандартов деятельности юридических услуг, которые были разработаны уральским некоммерческим партнерством «Объединение участников рынка правовых услуг Национальная правовая палата». Этот документ включает в себя три стандарта: «Квалификация лиц, оказывающих юридические услуги», «Дисциплинарные процедуры», «Принятие поручений в системе отношений с клиентами». Преимуществами этого документа является то, что в нем перечислены необходимые условия юридической деятельности субъектов, например, необходимо иметь высшее юридическое образование, стаж работы не менее двух лет по юридической специальности, должны отсутствовать дефекты дееспособности. Также необходимо наличие помещения и оборудования, которое обеспечит сохранность документов и конфиденциальность общения с клиентом; обязательна процедура письменного оформления договора на предоставление юридических услуг.

Кроме положительных сторон, у уральских стандартов имеются недостатки. В этих требованиях не установлены требования к качеству процесса оказания самой услуги. В этом отношении уральские стандарты напоминают законодательные нормы для адвокатов - практически нет положений о качестве самой услуги, но много требований к личности юриста, его подготовке и т.д.

Еще одним примером стандартизации юридических услуг являются Стандарты профессиональной деятельности юристов «Правовое обеспечение в сфере здравоохранения», утвержденные некоммерческим партнерством «Объединение участников профессиональной деятельности в сфере здравоохранения «Право в здравоохранении». Такой стандарт разработан для юристов узкой специализации.

\section{Baikal Research Journal}

электронный научный журнал Байкальского государственного университета 
Но информации о критериях процесса оказания юридической услуги, о действиях, которые должны являться обязательными, в нем не содержится [6, с. 32].

Внутрифирменные стандарты разрабатываются наиболее ответственными и конкурентными фирмами по желанию. Они преследуют следующие цели: уточнение процесса производства услуги для своих работников, использование для оценки качества их работы, для совершенствования системы стимулирования работников, обучения новых сотрудников и для других потребностей совершенствования менеджмента услуг. Стандарты способствуют повышению конкурентоспособности фирмы на рынке юридических услуг. В таких стандартах есть правила общения с клиентом, как должен себя вести юрист, что должен делать и т.п. Наличие этих стандартов позволяет еще до обращения к юристу изучить должный уровень качества услуги. Более того, обращение в фирму с наличием таких стандартов, делает клиента более защищенным в своих правах, так как несоблюдение стандартов считается нарушением прав потребителя. $K$ сожалению, такие стандарты обязательны только для тех субъектов рынка, которые добровольно приняли и соблюдают свои корпоративные стандарты.

Обсудим некоторые стороны работы юристов с населением для уточнения роли стандартов. Для клиента самое главное в услуге - это результат. За положительный исход дела клиент готов смириться с различными негативными аспектами общения с юристом, недоброжелательностью, уклонением юриста от общения, неблагоприятными отзывами о нем и т.п. Но если результат оказанной услуги клиенту не подходит, то никакие объяснения объективных причин его не устроят. [11, c. 644]. В то же время, на момент обращения клиента за услугой к юристу практически нет возможности прогнозировать результат судебного процесса. И добросовестный юрист не станет давать гарантию достижения положительного результата.

Юрист рассматривает качество своей деятельности с позиции соответствия его действий требованиям законодательства и может гарантировать только добросовестное отношение к делу и исполнительность при использовании законных средств защиты интересов, а клиента интересует исключительно умение юриста добиться положительного результата.

Положительная роль стандартов ярко проявляется в работе адвоката, по сравнению с другими субъектами производства услуг, на которых не распространяются законодательные нормы адвокатов.

Истоки такой позиции юриста зависят от правовых основ оценки качества услуг и содержатся в Кодексе профессиональной этики адвоката. Формально Кодекс распространяется только на адвокатов, но по сути утверждения о результатах оказания услуг должны относиться ко всем юристам и выполняться ими. А именно, в п.2 ст.10 Кодекса сказано, что адвокат не вправе обещать клиенту положительный результат выполнения поручения [12, с. 28]. Следовательно, юрист никакого положительного результата обещать клиенту не может, но сами клиенты, в большинстве случаев, об этом не осведомлены.

Причиной такого отношения клиента к деятельности юриста является правовая малограмотность населения, получение информации о работе юриста из голливудских фильмов, которые искажают реальность и практически не имеют ничего общего с правовой жизнью в России. Чтобы эффективно защищать свои права, нужно иметь представление о требованиях законов, но вместо изучения законодательства граждане нередко, наоборот, стараются «забывать» действительность, просматривая различные телешоу о правовых явлениях, в которых форма доминирует над содержанием. Полученная информация из таких источников не имеет ничего общего с реальными судебными процессами. А более серьезные пе-

\section{Baikal Research Journal}

электронный научный журнал Байкальского государственного университета 
редачи обычно менее доступны для восприятия населением из-за отсутствия или недостатка информированности об основах юриспруденции.

Нельзя сказать, что российское общество абсолютно неграмотно в правовой сфере, но нужно признать, что существующих знаний граждан недостаточно для грамотного использования своих прав. Проблема россиян в том, что они сами не хотят овладевать правовой информацией, а к юристам обращаются уже тогда, когда приобрели своими действиями какие-либо обязательства, из-за своего бездействия пропустили сроки, установленные законом [13, с. 37]. В таком случае сразу помочь человеку решить проблему практически невозможно, нужно исправлять это в судебном порядке. А так как незнание закона не освобождает от ответственности, результатом отсутствия знаний о законах могут быть различные неблагоприятные последствия для человека.

Многие россияне не обладают знаниями правовых основ, например, при походе в магазин не осведомлены о том, какие сопроводительные документы должны быть в наличии, особенно при покупке технически сложного товара.

Если произошла покупка некачественного товара, то для его обмена в магазин возвращается лишь небольшое количество людей, считая что это бесполезно и забывая, что в России есть не только федеральные, но и региональные и муниципальные органы, в которые можно обратиться с соответствующей жалобой, если права потребителя были нарушены.

В большинстве случаев покупатели не знают, что кроме кассового чека они имеют право получить товарный чек. И только немногие знают, что продавца можно попросить показать соответствующую сертификацию на товар, имеющийся в наличии.

Следует признать, что юридические знания для многих людей в России не являются большой ценностью. Такое отношение населения к юриспруденции мешает успешному развитию права, законности, а также правовой культуры населения $[14$, c. 39$]$.

Если вспомнить советские времена и годы перестройки, то для правового просвещения населения в России создавались благоприятные условия: выпускались различные периодические издания с привлечением квалифицированных ученых-правоведов, юрисконсультов, работников правоохранительных органов и т.п. Велась активная деятельность по разъяснению законов, правовому воспитанию и обучению со школьного возраста, чтение лекций по праву, выступления высококвалифицированных юристов по радио и телевидению.

В современной России практически отсутствует научно-популярная литература по правовой тематике, а периодические издания не успевают за изменениями в законодательстве. Во многих периодических изданиях не предусмотрены специальные рубрики для статей по юридической тематике, поэтому такой материал появляется несистематически, случайно. Более того, в современных статьях часто встречаются ошибки и неточности, связанные с отсутствием знаний либо неправильным истолкованием, объяснением законов самими журналистами [15, с. 74]. Актуальной сегодня является ориентация публикаций в область уголовно-правовой проблематики, хотя с уголовными преступлениями соприкасается намного меньше людей, чем с трудовыми, семейными и другими гражданскими спорами.

Итак, несмотря на наличие документов, относящихся к производству коммерческих юридических услуг для населения, основная юридическая деятельность остается без должного регулирования качества.

Таким образом, качество юридических услуг для населения частично регулируется государственными документами, а именно Федеральным законом «Об адвокатской деятельности и адвокатуре в Российской Федерации», «Кодексом профес-

\section{Baikal Research Journal}

электронный научный журнал Байкальского государственного университета 
сиональной этики адвоката», Федеральным Законом «О бесплатной юридической помощи в Российской Федерации", различными процессуальными кодексами.

Процесс оказания юридических услуг регулируется стандартами на уровне организаций и ассоциаций юристов, например, Стандартами профессиональной деятельности, разработанными партнерством «Объединение участников рынка правовых услуг Национальная правовая палата». Условиями оказания юридических услуг в данном стандарте является высшее юридическое образование для субъекта, оказывающего услугу, стаж работы не менее двух лет по юридической специальности, отсутствие дефектов дееспособности, наличие помещения и оборудования, обеспечивающего сохранность и конфиденциальность документов, необходимость письменного оформления договора на оказание юридических услуг.

Проанализировав данные документы, можно сделать вывод о том, что процесс и результат оказания самой юридической услуги в должной мере не регулируется ни на законодательном уровне, ни на уровне организаций и ассоциаций юристов.

Между тем, нужно отметить, что оказание юридической услуги необходимо основывать на стандартах, которые требуют верного расчета размера государственной пошлины или цены иска, правильного определения сторон судебного спора, разработки позиции по делу с учетом изменений в законах и т.д.

В результате проведенного исследования можно сделать вывод о важности введения стандартов качества юридических услуг для населения. Это необходимо современному профессиональному сообществу юристов, так как улучшило бы оказание таких услуг и снизило асимметрию информации между клиентом и юристом.

\section{Список использованной литературы}

1. Новаторов Э. В. Маркетинг услуг: теория и технологии : монография / Э. В Новаторов - СПб. : ИП Петров Д. А., 2015. - 200 с.

2. Полякова Н. В. Юридические услуги для населения / Н. В. Полякова, Ю. О. Банарова, В. В. Поляков // Известия Байкальского государственного университета. 2017. - Т. 27. № 2. - C. 146-153.

3. Мельниченко Р. Г. Адвокаты избавились от страха / Р. Г. Мельниченко // Адвокатская практика. - 2010. - № 1. - С. 29-32.

4. Мельниченко Р. Г. Виды мер профессиональной ответственности адвокатов / Р. Г. Мельниченко // Адвокатская практика. - 2011. - № 1. - С. 23-26.

5. Чашин А.Н. Стандарты качества юридических услуг / А. Н. Чашин. - М. : Дело и Сервис, 2013. - 96 с.

6. Воронов А. А. Преступления и наказания адвокатов (отзыв на монографию Р. Г. Мельниченко «Правовое регулирование института профессиональной ответственности адвокатов в Российской Федерации" /А. А. Воронов // Адвокат. - 2010. - № 11. - С. 37-38.

7. Горовенко В. В. Методологические проблемы правовой активности / В. В. Горовенко // Право и бизнес: сборник статей I ежегодной международной научно-практической конференции, приуроченной к 80-летию со дня рождения профессора В.С. Мартемьянова / М. Ю. Абрамкина [и др.] ; под. ред. И. В. Ершовой. - М. : Юрист, 2012. - 770 с.

8. Мишин В. М. Управление качеством / В. М. Мишин. - М. : Юнити-Дана, 2005. $463 \mathrm{c}$. $179 \mathrm{c}$.

9. Гренроос К. Маркетинг и менеджмент услуг / К. Гренроос. - М. : Прогресс, 1990. -

10. Лавлок К. Маркетинг услуг: персонал, технологии, стратегии / К. Лавлок. - М. : Вильямс, 2005. - $982 \mathrm{c}$.

11. Минасян А. В. Понятие адвокатской деятельности и отграничение её от смежных видов юридической деятельности / А. В. Минасян // Учёные труды Российской Академии адвокатуры и нотариата. - 2009. - № 2 (13). - С. 22-31.

12. Остапенко П. И. Средства массовой информации в механизме формирования ценностно-правовых ориентаций и массового правосознания россиян / П. И. Остапенко, О. О. Спицына. - Краснодар, 2011. - 183 с.

\section{Baikal Research Journal}

электронный научный журнал Байкальского государственного университета 
13. Асфандиаров Б. М. Правовая культура и правовое образование - актуальное направление образования молодёжи / Б. М. Асфандиаров // Юрист вуза. — 2012. — № 5. C. $37-46$.

14. Мартынкина Д. Ю. Правовое просвещение населения через печатные СМИ: история и современность / Д. Ю. Мартынкина // Вестник Московского университета. — 2010. № 5. - C. $72-79$.

\section{Reference}

1. Novatorov E. V. Marketing uslug: teoriya i tekhnologii [Marketing of services: theory and technology]. Saint Petersburg, Petrov D. A. Publ., 2015. 200 p.

2. Polyakova N. V., Banarova Yu. O., Polyakov V. V. Legal service to the public. Izvestiya Irkutskoi gosudarstvennoi ekonomicheskoi akademii = Bulletin of Baikal State University, 2017, Vol. 27, no. 2. pp. 146-153.

3. Mel'nichenko R. G Lawyers have recovered from fright. Advokatskaya praktika = Lawyer's Practice, 2010, no. 1. pp. 29-32. (In Russian).

4. Mel'nichenko R. G. Quality standards of lawyers' services. Advokatskaya praktika= Lawyer's Practice, 2011, no. 1. pp. 23-26. (In Russian).

5. Chashin A.N. Standarty kachestva yuridicheskikh uslug [Standards of legal service quality]. Moscow, Delo i Servis Publ., 2013. 96 p.

6. Voronov A. A. Crimes and punishment of lawyers (Report on R. G. Melnichenko's monography "Legal regulation of institution of lawyers' professional responsibility in the Russian Federation. Advokat $=$ Lawyer, 2010, no. 11. pp. 37-38. (In Russian).

7. Gorovenko V. V. Methodological problems of legal activity. In. I. V. Ershova (ed.) Pravo i biznes: sbornik statei I ezhegodnoi mezhdunarodnoi nauchno-prakticheskoi konferentsii, priurochennoi $k$ 80-letiyu so dnya rozhdeniya professora V.S. Martem'yanova = Law and Business: Collection of Articles of 1-st Annual International Science and Practice Conference Confined to 80-th Birthday of Professor V.S. Martemyanov, Moscow, Yurist Publ, 2012. 770 p. (In Russian).

8. Mishin V. M. Upravlenie kachestvom [Quality Management]. Moscow, Yuniti-Dana Publ, 2005. $463 \mathrm{p}$.

9. Gronroos. C. Strategic Management and Marketing in the Service Sector, Helsingfors Swedish School of Economics, 1982.

10. Lovelock C., Wirtz J. Services marketing : people, technology, strategy. 4 ed. New Jersey, Pearson Education LTD, 2001. 389 p.

11. Minasyan A. V. Concept of lawyer's activity and its restriction from related types of law activity. Uchenye trudy Rossiiskoi Akademii advokatury $i$ notariata = Learned Writings of Russian Academy of the Bar and Notaryship, 2009, no. 2 (13). pp. 22-31. (In Russian).

12. Ostapenko P. I., Spitsyna O. O. Sredstva massovoi informatsii $v$ mekhanizme formirovaniya tsennostno-pravovykh orientatsii $i$ massovogo pravosoznaniya rossiyan [Means of mass information in mechanism of developing value-legal orientations and mass legal sense of Russians Krasnodar]. Krasnodar, 2011. 183 p.

13. Asfandiarov B. M. Legal culture and legal education - topical direction of youth education. Yurist vuza = University Lawyer, 2012, no. 5. pp. 37-46. (In Russian).

14. Martynkina D. Yu. Legal literacy of the public through printed media: history and modern times. Vestnik Moskovskogo universiteta = Bulletin of Moscow University, 2010, no. 5. pp. 72-79. (In Russian).

\section{Информация об авторе}

Баранова Юлия Олеговна - аспирант, кафедра менеджлента, маркетинга и сервиса, Байкальский государственный университет, 664003, г. Иркутск, ул. Ленина, 11, e-mail: yulishka.92@mail.ru.

\section{Author}

Yulia O. Baranova - PhD Student, Chair of Management, Marketing and Services, Baikal state University, 11 Lenin St., 664003, Irkutsk; e-mail: yulishka.92@mail.ru.

\section{Baikal Research Journal}




\section{Для цитирования}

Баранова Ю.О. Роль стандартов в обеспечении качества юридических услуг для населения / Ю.О. Баранова // Baikal Research Journal. — 2017. — T. 8, № 3. — DOI : 10.17150/2411-6262.2017.8(3).14.

\section{For Citation}

Baranova Yu.O. Role of standards in providing quality legal services to the public. Baikal Research Journal, 2017, vol. 8, no. 3. DOI: 10.17150/2411-6262.2017.8(3).14. (In Russian).

\section{Baikal Research Journal}

